\title{
言語プロトコルの潜在意味解析モデルによる 消費者の選好分析
}

\author{
玉利 祐樹1 竹村 和久 早稲田大学
}

\begin{abstract}
Analyzing consumer preference by using the latest semantic model for verbal protocol
\end{abstract}
Yuki Tamari and Kazuhisa Takemura (Waseda University)

\begin{abstract}
This paper examines consumers' preferences for competing brands by using a preference model of verbal protocols. Participants were 150 university students, who reported their opinions and feelings about McDonalds and Mos Burger (competing hamburger restaurants in Japan). Their verbal protocols were analyzed by using the singular value decomposition method, and the latent decision frames were estimated. The verbal protocols having a large value in the decision frames could be interpreted as showing attributes that consumers emphasize. Based on the estimated decision frames, we predicted consumers' preferences using the logistic regression analysis method. The results indicate that the decision frames projected from the verbal protocol data explained consumers' preferences effectively.
\end{abstract}

Key words: consumer behavior, verbal protocol, latent semantic analysis.

The Japanese Journal of Psychology

2012, Vol. 82, No. 6, pp. 497-504

消費者は各々が重視する属性に基づいて，ブランド を選択していると考えられる。消費者の重視する属性 を明らかにすることは, 競合するブランドとの差別化 や製品開発において重要である。身近な例として，フ アストフードチェーンのマクドナルドとモスバーガー を挙げる。マクドナルドとモスバーガーは, 1995 年 から 2006 年まで他を抑えそれぞれ売上高 1 位と 2 位 を保っている（水越, 2008）。マクドナルドは低価格, 一等地への出店, 徹底したマニュアルという戦略を採 っているとされる。このことから，消費者は価格や店 舗へのアクセスの良さを重視していると考えられる。 一方，モスバーガーは品質重視，二等地への出店とい う戦略を採っているが, マクドナルドと同様に低価格 戦略を採っていたロッテリアを抑え，売上高 2 位を保 っている。戦略の異なる 2 ブランドが売上の上位 1

Correspondence concerning this article should be sent to: Kazuhisa Takemura, Department of Psychology, Waseda University, Toyama, Shinjuku-ku, Tokyo 162-8644, Japan (e-mail: kazupsy@ waseda.jp)

1 本研究の実施やデータの整理にあたり, 早稲田大学大学院 文学研究科の井出野 尚氏, 大久保重孝氏, 早稲田大学第一文 学部 (当時) の齋藤麻理恵氏, 早稲田大学の James M. Verdaman 教授には大変お世話になりました。ここに記して謝意 表します。
位，2 位を占める状況では，消費者が重視する属性を 明らかにすることは特に重要である。

消費者が重視する属性の探索に有効な手法として, 過程追跡法 (process tracing method; Bettman \& Park, 1980a, b; Bettman \& Zins, 1977; Payne, Bettman, \& Johnson, 1993）の一つである言語プロトコル法（verbal protocol) が挙げられる。言語プロトコル法は Ericsson \& Simon（1993）によって体系づけられた手 法であり, 意思決定課題中に頭に思い浮かんだこと を，逐次そのまま発話報告させるものである（阿部, 1984; Araña \& León, 2009; Payne \& Braunstein, 1978; Payne, Braunstein, \& Carrol, 1978; Williamson, Ranyard, \& Cuthbert, 2000)。消費者行動研究の心理 学的研究では, ブランド選択などの意思決定場面で, 消費者がどのようにして選択肢の属性を検討している のかといった, 消費者の情報処理過程を検討する際に 用いられる (Bettman, Luce, \& Payne, 1998; Payne, 1976a, b)。

言語プロトコル法には以下のような利点がある（阿 部, 1984; Fleck \& Weisberg, 2004; 竹村・高木, 1987)。第 1 に意思決定の最中に考えられている要因 が, 言語報告という直接的な形で出てくることが期待 できること (Ericsson \& Simon, 1993)，第 2 に言語プ ロトコルデー夕は意思決定課題中に時系列に沿って報 
告されるため, プロセスに関する情報を自然な形で含 んでいることである。また，自由に言語報告をさせる ため, 想定外の意見や情報を得ることも期待され，言 語プロトコルから豊富な情報を得ることができる (Newell \& Simon, 1972)。

一方で，言語プロトコルデータの分析については， 様々な問題が指摘できる。言語プロトコルデータの分 析では，ディシジョンネットの作成，または言語プロ トコルデータを分類し意思決定方略を分析することが 多い。これらの分析は消費者が採った意思決定方略を 明らかにしうるが，その意思決定方略がどの程度消費 者の意思決定を説明できるのかについての情報を，必 ずしも定量的に得ることはできない。また，発話者の 観点に依存して, 同じ言葉であっても言語プロトコル データが持つ意味合いはかなり変わると考えられる。 しかし，通常言語プロトコルデータ中の一つの単語は 一つのカテゴリに対応づけられて分析されるため, 発 話者の観点が分析に反映されているとは必ずしも言え ない。

以上より，言語プロトコル法を用いることで人の情 報処理過程を直接的に観察し, 豊富な情報を得ること ができるが，その分析にあたっては，より定量的な議 論を可能とし, 言語プロトコルデータとして得られる 表面的な語彙の分析では捉えきれない発話者の潜在的 な観点の探索を可能とする手法の適用が望まれる。

竹村・若山・堀内（2004）は, 言語プロトコルデー 夕が持つ情報の豊富さを活かしつつも，定量的な分析 と言語プロトコルデータが発せられる背景の探索を可 能とする計量モデルを提案している。竹村他（2004） のモデルでは，言語プロトコルデータは選好を導くと 仮定し，言語プロトコルデータ中の意思決定に関わる 属性の探索抢よび，その属性が意思決定に与える影響 を定量的に評価する。また，言語プロトコルデータの 背後に決定フレームの存在を仮定する。決定フレーム とは, 意思決定者がある意思決定問題に直面した際に 抱く, その問題に扔ける選択肢に関連する行動, 結 果，偶発性等に関する一定の傾向を持つ考えである （Tversky \& Kahneman, 1981）。決定フレームは意思決 定問題における状況に依存して様々に変化するため, 客観的に同一の選択肢であっても, 決定フレームの差 異に従い, 意思決定者がその選択肢に抱く印象が全く 異なることがある。決定フレームを用いて意思決定を 捉えることで, 微細な状況の変化に対応した決定フレ 一ムの変化と, 決定フレームの変化による意思決定結 果の変化を説明する。しかし，このモデルは提案され てはいるものの，実際の選好デー夕を用いて分析がな されていない。そこで本論文ではモデルの適用を行 い, 競合状況にあるブランドに対する消費者の選好分 析を行う。竹村他（2004）のモデルに基づき, 各ブラ ンドに対する言語プロトコルデータを用いて, ブラン
ド選択における選好分析を行い，またブランド選択に 関わる決定フレームとその決定フレームの中で注目さ れる属性の探索を行う。

$$
\text { モ デル }
$$

竹村他（2004）のモデルを概説する。消費者の意思 決定は多属性意思決定であると仮定する。ブランド $r$ を $q$ 次元の属性 $x_{k}$ よりなる選択肢 $X_{r}$ と考える。ここ で決定フレームの集合 $F$ および，言語表現の集合 $L$ を考え，それぞれについて確率が設定できるとする。 このときに，消費者がある状況 $j$ において言語表現 $l_{j}(\in L)$ を行っているときに, ある一定の決定フレー 厶 $f_{i}(\in F)$ が確率的に喚起されると仮定する。つま り, 離散的な構造化された類型として存在するのでは なく, 多次元空間を連続的に変移する点であると考え る(竹村・高木, 1987)。言語表現 $l_{j}$ のもとで決定フ レーム $f_{i}$ が出現する条件付き確率を $p\left(f_{i} \mid l_{j}\right)$ とおく。 消費者が言語表現 $l_{j}$ をしている時の属性 $x_{k}$ に対する注 目率として, 焦点パラメータ $\alpha_{j k}$ を,

$$
\alpha_{j k}=\sum_{i=1}^{m} p\left(f_{i} \mid l_{j}\right) m\left(f_{i}, x_{k}\right)
$$

と定義する。ただし $m\left(f_{i}, x_{k}\right)$ は属性 $x_{k}$ が決定フレ 一ム $f_{i}$ の構成要素に含まれる度合いである。そして, $X_{r}$ の効用を $U\left(X_{r}\right)$ とし, 焦点パラメータ $\alpha_{j k}$ の関数 として表現する。ここでは, 線形モデルを仮定して以 下のように表現する。

$$
U\left(X_{r}\right)=\sum_{k=1}^{q} \alpha_{j k} u\left(x_{r k}\right)
$$

潜在意味解析 次に, 決定フレームを言語プロトコ ルデータから推定する方法を述べる。竹村他（2004） では, 言語プロトコルデータから推定される決定フレ 一ム $f_{i}$ は数多くの単語から構成される集合であり, ま た個々の単語を属性 $x_{k}$ であると考え, 決定フレーム の推定に潜在意味解析（latent semantic analysis：以下 LSA とする; Deerwester, Dumais, Furnas, Landauer, \& Harshman, 1990）を適用する。

LSA では, 文書と単語の共起行列を特異值分解し, 文書および単語の背後にある潜在次元のそれぞれの特 徵べクトルを求める。サイズが $s \times t$ である共起行列 を $\boldsymbol{A}$ とおき，これを特異值分解する。ただし， $s$ は文 書の数, $t$ は単語の数を表す。

$$
\boldsymbol{A}=\boldsymbol{U} \Sigma V^{\prime}
$$

ここで, $A$ のランクを $r$ とすると, $\boldsymbol{\Sigma}$ は対角要素が特 異值である $r \times r$ 対角行列である。 $\boldsymbol{U}$ と $\boldsymbol{V}$ は正規直交 行列であり, サイズはそれぞれ $s \times r, t \times r$ である。次 に, 単語間の類似度を表す行列積 $\boldsymbol{A}^{\prime} \boldsymbol{A}$ を特異值分解 し，以下のように展開する。

$$
\begin{aligned}
\boldsymbol{A}^{\prime} \boldsymbol{A} & =\boldsymbol{V} \boldsymbol{\Sigma}^{2} \boldsymbol{V} \\
& =(\boldsymbol{V} \mathbf{\Sigma})(\boldsymbol{V} \mathbf{\Sigma})^{\prime}
\end{aligned}
$$

これは $A^{\prime} を V \Sigma$ で近似できることを示している。こ 
の近似行列の列が，文書と単語の背後にある潜在次元 である。このようにLSAを用いることで, 潜在次元 における単語の特徵べクトルを探索できるようにな る。また，文書間の類似度を $A A^{\prime}$ とすれば， $U \Sigma$ に より潜在次元における文書の特徴べクトルを探索でき る。ここで，文書を消費者に置き換えると，LSAに より得られる潜在次元は, 消費者の言語プロトコルデ 一夕の背後にある潜在次元であると考えられる。竹村 他（2004）では，LSAにより求められる潜在次元を, 消費者の言語プロトコルデータの背後にある決定フレ ームとして扱う。

LSA を用いる利点をもう一点述べる。言語プロト コルデータを用いて消費者の選好を説明するにあた り, 消費者と単語の共起行列は多くの場合に疎行列で あると予想される。疎行列であるデー夕は，一般的な 統計解析に適しているとは言えず，消費者の選好を予 測する際の障害となる。LSAにより得られる特徵べ クトルは，疎ではなくなっており，また正規分布に従 うという性質を持つ。LSAにより求められた特徵べ クトルを用いることで, 言語プロトコルデータと消費 者の選好との関連をより検討しやすくなると考えられ る。

以上を踏まえ，本論文では決定フレームを使って消 費者の選好を説明する。まず，(1)式を利用して(2)式を 以下のように書き換える。

$$
\begin{aligned}
U\left(X_{r}\right) & =\sum_{k=1}^{q} \sum_{i=1}^{m} p\left(f_{i} \mid l_{j}\right) m\left(f_{i}, x_{k}\right) u\left(x_{r k}\right) \\
& =\sum_{i=1}^{m} p\left(f_{i} \mid l_{j}\right) \sum_{k=1}^{q} m\left(f_{i}, x_{k}\right) u\left(x_{r k}\right)
\end{aligned}
$$

ここで, $\sum_{k=1}^{q} m\left(f_{i}, x_{k}\right) u\left(x_{r k}\right)$ を行列表現する。 $u\left(x_{r k}\right)$ は, 消費者のインデックスを加え, 消費者と 単語の共起行列 $\boldsymbol{A}$ とする。また, LSA の潜在次元を 決定フレーム $f_{i}$ とすると, $\boldsymbol{V} \boldsymbol{\Sigma} は ~ m\left(f_{i}, x_{k}\right)$ を要素と する行列と解釈できる。ここでは， $\boldsymbol{V} \boldsymbol{\Sigma}$ の標準化され た值として $\boldsymbol{V}$ を用いる。 $\sum_{k=1}^{q} m\left(f_{i}, x_{k}\right) u\left(x_{r k}\right)$ は $\boldsymbol{A} \boldsymbol{V}$ と表現できる。 $\boldsymbol{A} \boldsymbol{V}$ は, (3)式より以下のように展開さ れ，消費者に関する近似行列 $\boldsymbol{U} \boldsymbol{\Sigma}$ に一致する。

$$
\begin{aligned}
\boldsymbol{A} \boldsymbol{V} & =\boldsymbol{U} \boldsymbol{\Sigma} \boldsymbol{V}^{\prime} \boldsymbol{V} \\
& =\boldsymbol{U} \boldsymbol{\Sigma}
\end{aligned}
$$

したがって, $\sum_{k=1}^{q} m\left(f_{i}, x_{k}\right) u\left(x_{r k}\right)$ は消費者に関する 近似行列 $\boldsymbol{U} \boldsymbol{\Sigma}$ の要素と考えることができる。 $p\left(f_{i} \mid l_{j}\right)$ を回帰係数 $\beta_{i j}$ とすれば, 回帰分析により $U\left(X_{r}\right)$ と消 費者に関する近似行列 $\boldsymbol{U} \boldsymbol{\Sigma}$ から $p\left(f_{i} \mid l_{j}\right)$ を推定し， $U\left(X_{r}\right)$ に対して最も当てはまりの良い決定フレーム $f_{i}$ を明らかにすることも可能である。

さらに, (9)式から消費者に関する近似行列の各列は $V$ の各列と一対一に対応していることがわかる。つま り, $\boldsymbol{U} \boldsymbol{\Sigma}$ から消費者の選好と関連する決定フレーム $f_{i}$ を明らかにし，その決定フレーム $f_{i}$ と対応する $V$ を 観察することで, 決定フレーム $f_{i}$ において大きな影響
を持つ単語を探索することができる。なお, $p\left(f_{i} \mid l_{j}\right)$ は比尺度であるが, 本論文では,

$$
p\left(f_{i} \mid l_{j}\right) \propto \beta_{i j}
$$

と考え， $\beta_{i j}$ を $p\left(f_{i} \mid l_{j}\right)$ の近似として用いることとする。

\section{方法}

調査 自由記述と描画による回答を求めるブランド イメージ調査を行った。ブランドイメージ調查は必ず しも明示的なブランドの比較として行われるわけでは ない。そういった調査からであっても，ブランドを差 別化する属性を探索するために，ブランドに対するイ メージを個々に回答させる形式とした。競合状況下の ブランドとして, マクドナルドとモスバーガーの二つ を取り上げた。本論文では, 調査参加者に言語報告に 加え描画による回答を求めるため, 調查参加者の回答 のしやすさおよび言語データの収集と取り扱いの簡便 さを考慮し, 自由記述による回答を求めることとし た。描画による回答は, 社会的なタブーに抵触する話 題，または回答者が幼いなどの理由のため言語報告が 困難な場合に用いられる（Takemura，Takasaki，\& Iwamitsu, 2005)。言語報告では表れにくいものが, 描 画による報告で表れる可能性を考慮して，描画による 回答を求めることとした。

調査参加者 $\mathrm{N}$ 県の私立大学生 150 名を対象とし て集団にて実施した。

手続き A4 用紙 4 枚と硬度 B の鉛筆を用い, マク ドナルドとモスバーガーに関するイメージの絵を 1 枚 ずつ描いてもらい, 残りの 2 枚にそれぞれのブランド の好きなところと嫌いなところを自由記述してもらっ た。また，好みの表明と実際の行動とは食い違うこと があるため, 二つの異なる側面から消費者の効用を検 討するために, 各ブランドに対して好意度を 0 点（全 然好きでない）から 10 点（かなり好き）までの 11 件 法にて評価してもらい, 利用頻度を月に何回利用する かで回答を求めた。

データ 自由記述，描画表現，好意度，および利用 頻度のいずれかに久損, 回答不備のあった調查参加者 22 名を除いて, 調査参加者 128 名を分析対象とした。 以下では自由記述, 好意度, 利用頻度のみを分析対象 とした。

自由記述に関しては，集団での実施により 1 文が非 常に短いものとなったため, 第 1 著者抢よび大学生 1 人がそれぞれ独立に, 商品, 印象や評価への分類を行 った。一致率は $77.2 \%$ であった。不一致があった 22.8 $\%$ の項目に関しては 2 者間で協議を行い, 協議の結果 をもとに分類を行った。また，両ブランドのどちらか で調查参加者 2 名以上が用いた項目を分析対象とし た。分析対象とした分類後の項目および，その項目を 使用した調查参加者の人数を Table 1 に示した。

各調查参加者が分析対象とした項目を用いていたか 
Table 1

分類後の項目

\begin{tabular}{|c|c|c|c|c|c|}
\hline 項目 & 人数 & 項目 & 人数 & 項目 & 人数 \\
\hline おまけ & 21 & 環境：良 & 4 & 食感：良 & 8 \\
\hline キャラクタ & 23 & 客 : 多 & 8 & 食器 & 5 \\
\hline グレード：高 & 11 & 客層 : 学生 & 4 & 接客：マニュアル的 & 5 \\
\hline グレード：貧 & 5 & 客層：子供 & 8 & 接客：悪 & 15 \\
\hline ゴミ & 2 & 客層 : 若者 & 5 & 接客：良 & 15 \\
\hline サービス：クーポン & 15 & 客層：女性 & 2 & 鮮度：古 & 5 \\
\hline サービス：テイクアウト & 3 & 客層：大人 & 4 & 鮮度 : 新 & 18 \\
\hline サービス：ドライブスルー & 16 & 健康：悪 & 25 & 素材 : ソース & 5 \\
\hline サービス：禁煙席 & 3 & 健康：良 & 10 & 素材 : その他 & 3 \\
\hline たまり場 & 3 & 見た目：悪 & 6 & 素材 : パン & 16 \\
\hline ロゴマーク & 6 & 広告 & 13 & 素材 : ピクルス & 4 \\
\hline 安全性：悪 & 21 & 高カロリー & 12 & 素材：肉 & 8 \\
\hline 安全性：良 & 25 & 手軽 & 14 & 素材：野菜 & 21 \\
\hline 椅子：悪 & 8 & 手作り & 3 & 素材：油 & 4 \\
\hline 印象：アメリカ & 4 & 商品：100 円 & 12 & 待ち合わせ & 2 \\
\hline 印象：お酒落 & 8 & 商品 : オニオンリング & 10 & 知名度 : マイナー & 2 \\
\hline 印象：悪 & 2 & 商品：ご飯 & 2 & 知名度：メジャー & 2 \\
\hline 印象：可愛い & 8 & 商品：サイズ : 小 & 2 & 提供時間：早 & 42 \\
\hline 印象：気軽 & 9 & 商品：サイズ：大 & 11 & 提供時間：遅 & 24 \\
\hline 印象：気軽でない & 13 & 商品：サラダ & 3 & 店舗：狭 & 7 \\
\hline 印象：気味が悪い & 3 & 商品：シェイク & 11 & 店舗数：少 & 13 \\
\hline 印象：五月蝿い & 5 & 商品：スープ & 5 & 店舗数：多 & 21 \\
\hline 印象：身近 & 6 & 商品：セット & 3 & 都市伝説 & 9 \\
\hline 印象：身近でない & 7 & 商品：その他 & 9 & 内装：悪 & 2 \\
\hline 印象：静か & 3 & 商品：チキン & 10 & 内装：良 & 6 \\
\hline 印象：素朴 & 3 & 商品：デザート & 16 & 匂い：悪 & 2 \\
\hline 印象：爽やか & 2 & 商品：ハンバーガー & 35 & 品質：悪 & 10 \\
\hline 印象：怖い & 11 & 商品：ポテト & 47 & 品質：質重視 & 5 \\
\hline 印象：明るい & 4 & 商品：飲料 & 12 & 品質：良 & 11 \\
\hline 印象：面白い & 5 & 商品：期間限定 & 10 & 品質：量重視 & 2 \\
\hline 印象：落ち着かない & 9 & 商品：形状 & 5 & 便利 & 3 \\
\hline 印象：落ち着く & 11 & 商品：種類：少 & 4 & 放送 & 10 \\
\hline 印象：良 & 9 & 商品：種類：多 & 33 & 味：まあまあ & 5 \\
\hline 印象：綺麗 & 7 & 商品：新商品：少 & 3 & 味：悪 & 40 \\
\hline 営業時間：長 & 15 & 商品：新商品：多 & 10 & 味：飽きない & 3 \\
\hline 衛生：悪 & 4 & 商品：朝限定 & 8 & 味：飽きる & 2 \\
\hline 衛生：良 & 4 & 商品：揚げスナック & 10 & 味：油っぽい & 12 \\
\hline 温度：温 & 4 & 色：良 & 2 & 味：良 & 107 \\
\hline 価格：安 & 102 & 食べやすさ：悪 & 14 & 友達 & 3 \\
\hline 価格：高 & 96 & 食べやすさ：良 & 3 & 量：少 & 15 \\
\hline 環境：悪 & 8 & 食感：悪 & 2 & 量：多 & 27 \\
\hline
\end{tabular}

否かを表す 2 值データをブランドごとに作成した。両 ブランドデータのサイズは 128 行 123 列であった。本 分析では，これらの項目を属性として扱う。

利用頻度に関しては, 幅のある場合は中央値を取 り, 小数点がつけられた場合は四捨五入した。月に 10 回以上利用すると回答した調査参加者が 3 名のみ
であったため, 10 回以上の回答は全て 10 回として扱 った。

好意度の平均值（標準偏差）は，マクドナルドは 5.56(2.46) であり，モスバーガーは 6.43(2.09) であ つた。利用頻度の平均值 (標準偏差) は, マクドナル ドは 1.98(2.15) であり，モスバーガーは 0.73(0.93) 
Table 2

好意度と利用頻度の相関係数 $(N=128)$

\begin{tabular}{|c|c|c|c|c|c|c|c|}
\hline & & \multicolumn{2}{|c|}{ Mcd } & \multicolumn{2}{|c|}{ Mos } & \multicolumn{2}{|c|}{ Mcd-Mos } \\
\hline & & 好意度 & 利用頻度 & 好意度 & 利用頻度 & 好意度 & 利用頻度 \\
\hline \multirow[t]{2}{*}{ Mcd } & 好意度 & 1 & & & & & \\
\hline & 利用頻度 & $.52 * * *$ & 1 & & & & \\
\hline \multirow[t]{2}{*}{ Mos } & 好意度 & -.12 & .06 & 1 & & & \\
\hline & 利用頻度 & $-.18^{*}$ & .14 & $.42 * * *$ & 1 & & \\
\hline \multirow[t]{2}{*}{ Mcd-Mos } & 好意度 & $.79 * * *$ & .34 & $-.70 * * *$ & $-.39 * * *$ & 1 & \\
\hline & 利用頻度 & $.57 * * *$ & $.91 * * *$ & -.12 & $-.29 * *$ & $.49 * * *$ & 1 \\
\hline
\end{tabular}

注） Mcd はマクドナルドを表し，Mosはモスバーガーを表す。

${ }^{*} p<.05, * *<.01, * * * p<.001$

であった。マクドナルドに対する值とモスバーガーに 対する值の差の平均值（標準偏差）は，好意度は -0.87(3.42) であり, 利用頻度は 1.25(2.22) であっ た。好意度においてはモスバーガーの值が高く，利用 頻度においてはマクドナルドの值が高い傾向が見られ た。また，好意度と利用頻度の相関係数を Table 2 に 示した。Table 2 より, 各ブランド内および差得点に おいて，好意度と利用頻度は正の相関を示した。

\section{結 果}

ブランド選択の説明を想定して，ロジスティック回 帰分析を行った。独立変数は調査参加者に関する近似 行列とした。従属変数は好意度と利用頻度とした。独 立変数に関して, 調査参加者の近似行列を求める際, 各ブランドデータを足し合わせたデータを用いた。な お, LSA では一般的に前処理として重み付けを行う が，本論文では北（1999）による重み付けを用いた。 ここでは，近似行列の各列が決定フレームを表すもの とし，特異值の上位 $10 \%$ にあたる 12 の決定フレーム を独立変数として用いた。従属変数は，好意度と利用 頻度ともに，両ブランドの值を比較して，マクドナル ドの值が高ければ 1 , モスバーガーの值が高いか同じ 值であれば 0 とした。ロジスティック回帰分析の結果 を Table 3 に示した。

なお, McFadden と Nagelkerke の疑似説明率は口 ジスティック回帰分析における説明率である。 McFadden と Nagelkerkeの疑似説明率は, 定数のみ のモデルの尤度と独立変数を組み込んだモデルの尤度 を比較して改善された程度を示す指標である。また, McFaddenの疑似説明率は, 独立変数が従属変数を説 明する程度を示す指標という側面も持つ。McFadden の疑似説明率は低い值をとる傾向があり, 0.2 から 0.4 の間の值が得られれば, その值は最小二乗法による線 形回帰分析における説明率 0.5 から 0.8 に相当し，乇 デルがデータに十分適合していると判断して良い (Domenrich \& McFadden, 1975; McFadden, 1979)。ま た, 回帰係数は, 正の值であればマクドナルドを選択
Table 3

疑似説明率と回帰係数

\begin{tabular}{lccc}
\hline & & 好意度 & 利用頻度 \\
\hline 疑似説明率 & McFadden & .19 & .26 \\
& Nagelkerke & .29 & .41 \\
\hline 回帰係数 & 定数 & 1.6 & $4.2^{*}$ \\
& $f_{1}$ & -33.6 & $-47.4^{*}$ \\
& $f_{2}$ & 3.5 & 8.9 \\
$f_{3}$ & -0.3 & -1.3 \\
$f_{4}$ & $-9.4^{*}$ & -1.5 \\
$f_{5}$ & 6.4 & 3.2 \\
& $f_{6}$ & $-17.4^{* *}$ & $-11.2^{* *}$ \\
$f_{7}$ & $-13.6^{*}$ & -5.4 \\
$f_{8}$ & 1.0 & $-9.0^{* *}$ \\
& $f_{9}$ & -4.2 & -2.5 \\
& $f_{10}$ & -0.1 & 1.1 \\
$f_{11}$ & -4.9 & $-7.0^{*}$ \\
$f_{12}$ & -1.3 & -4.8 \\
\hline
\end{tabular}

注） $f$ は決定フレームを表し, 下付きの数字は值が小さいほ ど特異值が大きい決定フレームであることを表す。

${ }^{*} p<.05, * * p<.01$

する確率が高まり，負の值であればモスバーガーを選 択する確率が高まることを示す。

Table 3 から, McFadden と Nagelkerke の疑似説 明率より，好意度に基づく選択の約 4 割が正しく分類 され，利用頻度に基づく選択の約 5 割が正しく分類さ れたことが示された。また，回帰係数は，従属変数が 好意度のときは $f_{4}, f_{6}, f_{7}$ が有意となり, 利用頻度の ときは定数項および $f_{1}, f_{6}, f_{8}, f_{11}$ が有意となった。 また，有意となった回帰係数は定数項を除いて全て負 の值を示した。これらのことから，好意度では上記に 示した三つの決定フレームが，また，利用頻度では上 記の四つの決定フレームが，モスバーガーを選択する ことを説明するのに有効である可能性が示された。

決定フレームの解釈 選好と関連する属性を確認す るために, 回帰係数が有意となった決定フレームに対 
Table 4

右特異ベクトル内の項目と值

\begin{tabular}{llll}
\hline \multicolumn{4}{c}{ 項目 (右特異ベクトルの值) } \\
\hline$f_{1}$ & 商品 : ポテト $(.21)$ & 商品 : ハンバーガー $(.19)$ & 提供時間 : 早 $(.18)$ \\
$f_{4}$ & 知名度 : マイナー $(.23)$ & 手軽 $(.19)$ & 店舗数 : 多 $(.17)$ \\
$f_{6}$ & 知名度 : マイナー $(.44)$ & 接客 : 良 $(.32)$ & 印象 : 気軽でない $(.31)$ \\
$f_{7}$ & 知名度 : マイナー $(.41)$ & 接客 : 良 $(.37)$ & 素材 : パン $(.21)$ \\
$f_{8}$ & 印象 : 落ち着かない $(.34)$ & 印象 : 落ち着く $(.34)$ & 印象 : 身近でない $(.29)$ \\
$f_{11}$ & 安全性 : 悪 $(.30)$ & 安全性 : 良 $(.25)$ & 品質 : 質重視 $(.20)$ \\
\hline
\end{tabular}

応する右特異べクトルを観察した。これらの属性は, ブランド選択にあたって注目される属性であると考え られる。右特異ベクトルの中で值が大きい上位 3 属性 を, 決定フレームを特徴づける属性とし, その属性と 右特異べクトルの值を Table 4 に示した。なお, この 右特異べクトルの值は- 1 から +1 まで取るが, 值が 大きいほどその決定フレーム中で注目されている属性 であると考えられる。

Table 4 に挙げた項目から, 決定フレームの解釈例 を以下に述べる。 $f_{1}$ の項目からファストフードのハン バーガーショップを表しており， $f_{4}$ では店舗数はあっ て手軽に利用できるが, 意外と思い出されない様を表 していると考えられる。また， $f_{6}$ と $f_{7}$ は隠れ名店を表 しているが, それぞれ雲囲気の側面と商品の側面が注 目されていると考えられる。そして， $f_{8}$ は漠然と居心 地に関するイメージを表しており， $f_{11}$ は食の安全を 表していると考えられる。なお， $f_{1}$ からは，まさにフ アストフードのマクドナルドが連想されるが, 回帰係 数は負の值であった。 $f_{1}$ のもとでは, モスバーガーが 選択される確率が高まることを示している。ファスト フードのイメージを嫌って，モスバーガーが選択され たものと考えられる。

\section{考察}

本論文では，竹村他（2004）による言語プロトコル データの計量モデルに基づき, 言語プロトコルデータ を用いて，競合状況にあるブランドの選択における選 好分析を行い，またそのブランド選択において注目さ れる属性の探索を行った。

本論文の手法で推定された決定フレームを用いるこ とで, 消費者のブランド選択の説明が可能であること が示された。また，各決定フレームにおける各属性へ の注目度から, その決定フレーム中の属性がブランド 選択に与える影響の定量的な評価が可能であることが 示された。しかしながら，ロジスティック回帰分析に おいて有意となった回帰係数は, 分析に用いた 12 の 独立変数のうち三つから四つであり, 決して多いとは 言えない。また，有意となった回帰係数は全て負の值 であり, モスバーガーを選択することしか説明できて
いない。本論文の結果は, 竹村他（2004）の意思決定 モデルを用いることで, 属性の重み付き集合で表現さ れる決定フレームから, 言語プロトコルデータにおけ る属性がブランド選択に与える影響の定量的な評価が 可能となることを示していると言える。今後は, 選好 をより説明する決定フレームを推定するために，言語 データ, 好意度および利用頻度データの収集法, コー ディング法, 竹村他（2004）のモデルとその実装にお ける問題を検討していく必要がある。

本論文では, 従来の言語プロトコル法の問題点をあ る程度は改善できたが, 分析前の自由記述データの扱 いに関して，2 人でコーディングした結果を用いてい る。人の手によるコーディングでは, 間主観性という 意味での客観性はある程度保証されるかもしれない が, 本来の意味での客観性が保証されているとは言え ない。今後は, 自然言語処理の技術などを用いた客観 的な分析を検討する必要がある。

本論文の結果の消費者行動研究への適用可能性を述 ベる。ハンバーガーショップの選択で重視する属性と してよく挙がるのは, 味と価格であり, 実際, 消費者 はこれらの属性を重視していると考えられる。しか し，回帰係数が有意となった決定フレームからは，消 費者は味や価格以外のその他の属性もかなり重視して いることが示唆された。このことは，本論文で用いた 分析を行うことで, 通常アンケートを行った際に数と して多くは挙がらない属性の中で, 選好と関連する属 性が抽出される可能性を示している。つまり，意見の 数だけを考慮していたのでは埋もれてしまう有用な意 見を適切に評価できる可能性があると言える。多くは 挙がらないが選好と関連する属性を探索できること は, 他ブランドとの差別化あるいは新たな製品開発に 対しての有用な示唆が期待できる。また, 今後, 社会 政策の決定などの実務的な方面で役立つことも期待さ れる。

また，通常，言語プロトコル法における発話は，課 題遂行場面で時系列に沿って行われる。これに対し て, 本論文で行った調査は, 1 時点のみの言語プロト コルデータと考えることができる。分析の結果から は, 1 時点のみの報告からでも複数の決定フレームが 
抽出されることが示され，またここれらの決定フレー ムの中には, 選好と関連するものがあることも示され た。たとえ 1 時点であっても, 複数の決定フレームが 消費者に生起しているものと考えられる。

決定フレームに含まれる属性に関して, 回帰倸数が 有意となった決定フレームに限っても, 複数の決定フ レームにまたがって大きな值を示す属性が存在した。 各決定フレーム内で大きな值を持つ属性の組み合わせ を考慮すると，決定フレームごとに同じ属性の異なる 側面が現れていると考えることができる。このように 言語プロトコルデータから推定される複数の決定フレ 一ムを用いることで，同じ属性を様々に解釈すること ができる。同じ属性を様々に解釈できることは，言葉 の持つ多義性を有効に活用できていると言える。

ただし，決定フレームの探索にLSA を用いること は，全ての決定フレームが相互に独立であると仮定し ていることを意味する。そのため, 理論上, 決定フレ 一ム間の相互関係については，本論文で用いた分析か らは明らかにできない。しかしながら，実際には，決 定フレームの間にはなんらかの繋がりがあることが予 想される。この決定フレーム間の関連を明らかにする ことができれば, この関連についての情報も他ブラン ドとの差別化および製品開発に対して有用な示唆が期 待できる。

なお，本論文では描画デー夕を分析対象から除外し たが，本論文で用いた手法を描画に対して適用するこ とも可能であると考えられる。今後は，描画に本論文 で用いた手法を適用し，さらに描画データと言語プロ トコルデータとの関係も考慮した分析を行っていく予 定である。

最後に，本論文で提案した分析手法や適用例は限ら れた領域のデー夕を用いており，またモデルの仮定を 過度に単純化している可能性があることを指摘しなけ ればならない。ただし，このような方法論的問題もあ るが，本論文で呈示した手法を用いることによって， 消費者の選好をより明らかにすることが期待できる。

\section{引用文献}

阿部 周造 (1984). 消費者情報処理理論 中西 正雄 (編著) 消費者行動分析のニュー・フロンティア 一多属性分析を中心に—誠文堂新光社 pp. 119-163.

(Abe, S.)

Araña, J. E., \& León, C. J. (2009). Understanding the use of non-compensatory decision rules in discrete choice experiments: The role of emotions. Ecological Economics, 68, 2316-2326.

Bettman, J. R., Luce, M. F., \& Payne, J. W. (1998). Constructive consumer choice processes. Journal of Consumer Research, 25, 187-217.
Bettman, J. R., \& Park, C. W. (1980a). Implications of a constructive view of choice for analysis of protocol data: A coding scheme for elements of choice processes. In J. C. Olson (Ed.), Advances in consumer research. Vol. 7. Ann Abor: Association for Consumer Research. pp. 148-153.

Bettman, J. R., \& Park, C. W. (1980b). Effects of prior knowledge and experience and phase of the choice process on consumer decision processes: A protocol analysis. Journal of Consumer Research, 7, 234-238.

Bettman, J. R., \& Zins, M. A. (1977). Constructive process in consumer choice. Journal of Consumer Research, 4, 75-85.

Deerwester, S., Dumais, S. T., Furnas, G. W., Landauer, T. K., \& Harshman, R. (1990). Indexing by latent semantic analysis. Journal of the American Society for Information Science, 41, 391-407.

Domenrich, T. A., \& McFadden, D. (1975). Urban travel and demand: A behavioural analysis. Amsterdam: North-Holland Publishing Company.

Ericsson, K. A., \& Simon, H. A. (1993). Protocol analysis: Verbal reports as data revised edition. Cambridge MA: MIT Press.

Fleck, J. I., \& Weisberg, R. W. (2004). The use of verbal protocols as data: An analysis of insight in the candle problem. Memory \& Cognition, 32, 9901006.

北研二 (1999)。言語と計算 4 確率的言語モデル 東京大学出版会

(Kita, K. (1999). Computation and language. Vol. 4. Probabilistic language model. Tokyo: University of Tokyo Press.)

McFadden, D. (1979). Quantitative methods for analysing travel behaviour of individuals. In D. A. Hensher \& P. R. Storper (Eds.), Behavioural travel modelling. London: Croom Helm. pp. 279-318.

水越康介 (2008)。ビジネス三国志(2) マック vs モ ス vs ロッテリア一一高付加価值戦略を検証する ハンバーガー 40 年戦争——勝者なき值下げ合 戦の教訓 プレジデント, 46(6), 146-151.

(Mizukoshi, K.)

Newell, A., \& Simon, H. A. (1972). Human problem solving. Englewood Cliffs, NJ: Prentice-Hall.

Payne, J.W. (1976a). Heuristic search processes in decision making. In B. B. Anderson (Ed.), Advances in consumer research. Vol. 3. Cincinnati, Ohio: Association for Consumer Research. pp. 321327.

Payne, J. W. (1976b). Task complexity and contingent processing in decision making: An information search and protocol analysis. Organizational Behavior and Human Performance, 16, 366-387.

Payne, J. W., Bettman, J. R., \& Johnson, E. J. (1993). The adaptive decision maker. Cambridge: Cambridge University Press.

Payne, J. W., \& Braunstein, M. L. (1978). Risky choice: An examination of information acquisitions behavior. Memory \& Cognition, 6, 554-561. 
Payne, J. W., Braunstein, M. L., \& Carrol, J. S. (1978). Exploring predecisional behavior: An alternative approach to decision research. Organizational Behavior and Human Performance, 22, 17-24.

竹村 和久 ・高木 修 (1987). 意思決定過程における 情報探索ストラテジーと内的状態——提供行動の 場合一一実験社会心理学研究, 26, 105-114.

(Takemura, K., \& Takagi, O. (1987). Information search strategies and inner states in the decision making processes: A case of donating behavior. Japanese Journal of Experimental Social Psychology, 26, 105-114.)

Takemura, K., Takasaki, I., \& Iwamitsu, Y. (2005). Statistical image analysis of psychological projective drawings. Journal of Advanced Intelligent Computing and Intelligent Informatics, 9, 453-460.

竹村 和久 · 若山 大樹 · 堀内 圭子 (2004). 広告受 容の数理心理モデルとデータ解析の開発——消費
者の判断と意思決定の心理実験と調査研究を通じ て一一広告科学, 45, 153-171.

(Takemura, K., Wakayama, D., \& Horiuchi, K. (2004). Development of mathematical psychology model and data analysis method for advertising communication: Using findings from psychological experiment and survey research of consumer judgment and decision making. Journal of Advertising Science, 45, 153-171.)

Tversky, A., \& Kahneman, D. (1981). The framing of decisions and the psychology of choice. Science, 211, 453-458.

Williamson, J., Ranyard, R., \& Cuthbert, L. (2000). A conversation-based process tracing method for use with naturalistic decisions: An evaluation study. British Journal of Psychology, 91, 203-221.

- 2009. 10. 29 受稿, 2011.9.6 受理一 